\title{
THREE DIMENSIONAL SYSTEM OF GLOBALLY MODIFIED MAGNETOHYDRODYNAMICS EQUATIONS WITH INFINITE DELAYS
}

\author{
G. Deugoue*, J. K. Djoko And A. C. Fouape
}

\begin{abstract}
Existence and uniqueness of strong solutions for three dimensional system of globally modified magnetohydrodynamics equations containing infinite delays terms are established together with some qualitative properties of the solution in this work. The existence is proved by making use of Galerkin's method, Cauchy-Lipshitz's theorem, a priori estimates, the AubinLions compactness theorem. Moreover, we study the asymptotic behavior of the solution.
\end{abstract}

Mathematics subject classification (2020): 26D15, 26A51, 32F99, 41A17.

Keywords and phrases: Magnetohydrodynamics equations, globally modified, strong solutions, infinite delays.

\section{REFERENCES}

[1] H. BRezIs, Functional Analysis, Sobolev Spaces and partial differential equations, Springer, 2010.

[2] T. Caraballo and J. Real, Navier-Stokes equations with delays, R. Soc. Lond. Proc. Ser. A Math. Phys. Eng. Sci., vol. 457 (2001), 2441-2453.

[3] T. Caraballo and J. Real, Asymptotic behaviour of two-dimensional Navier-Stokes equations with delays, R. Soc. Lond. Proc. Ser. A Math. Phys. Eng. Sci., vol. 459 (2003), 3181-3194.

[4] T. Caraballo and J. Real, Attractors for $2 D$-Navier-Stokes model with delays, J. Differential Equations, vol. 205 (2004), 271-297.

[5] T. Caraballo, J. Real, P. E. Kloeden, Unique strong solutions and $V$-attractors of a three dimensional system of globally modified Navier-Stokes equations, Adv. Nonlinear Stud., 6 (3) (2006), 411-436.

[6] T. Caraballo, P. E. Kloeden And J. Real, Invariant measures and statistical solutions of the globally modified Navier-Stokes equations, Discrete Continuous Dyn. Syst. Ser. B, vol. 10 (4) (2008), 761-781.

[7] T. Caraballo, J. Real and A. M. Márquez, Three-dimensional system of globally modified Navier-Stokes equations with delay, Int. J. Bifurcat. Chaos Appl. Sci. Eng., vol. 20 (9) (2010), 28692883.

[8] T. Caraballo and P. E. Kloeden, The three-dimensional globally modified Navier-Stokes equations: recent developments, in: A. Johann, H. P. Kruse, F. Rupp (eds.) Recent Trends in Dynamical Systems: Proceedings of a Conference in Honor of Jürgen Scheurle, pp. 473-492. Springer Proceedings in Mathematics and Statistics, vol. 35 (2013).

[9] S. Chandrasekhar, Hydrodynamic and Hydromagnetic Stability, in: The International Series of Monographs on Physics, Clarendon Press, Oxford, 1961.

[10] P. Constantin, C. Foias, Navier-Stokes Equations, in: Chicago Lectures in Mathematics, University of Chicago Press, Chicago, IL, 1988.

[11] T. G. Cowling, Magnetohydrodynamics, in: Interscience Tracts on Physics and Astronomy, vol. 4, Interscience Publishers, Inc., New York, 1957, Interscience Publishers, Ltd., London.

[12] G. Deugoué and J. K. Djoko, On the time discretization for the globally modified threedimensional Navier-Stokes equations, J. Comput. Appl. Math., vol. 235 (8) (2011), 2015-2029.

[13] G. Deugoué, J. K. Djoko, A. C. Fouapé, A. N. NGana, Unique strong solutions and V-attractor of a three dimensional globally modified magnetohydrodynamics equations, Commun. Pure. Appl. Anal., vol. 19 (3) (2020), 1505-1535. 
[14] G. Deugoué, J. K. Djoko, A. C. Fouapé, On the Convergence of Solutions of Globally Modified Magnetohydrodynamics Equations with Locally Lipschitz Delays Terms, QM., vol. 44, (4), (2021), $1-27$.

[15] G. Deugoué, J. K. Dјоко, A. C. Fouapé, Globally modified Navier Stokes equations coupled with the heat equation: existence and time discrete approximation, Journal of Applied Analysis and Computation, doi:10.11948/20200409.

[16] G. Duvaut, J. L. Lions, Inequalities in Mechanics and Physics, Grundlehren der Mathematischen Wissenschaften, vol. 219, Springer-Verlag, Berlin, New York, 1976.

[17] Y. Hino, S. Murakami, and T. Naito, Functional Differential Equations with Infinite Delay, Lecture Notes in Mathematics, 1473, Berlin: Springer-Verlag, 1991.

[18] D. D. Holm, J. E. MARSDEN AND T. S. RATIU, Euler-Poincaré models of ideal fluids with nonlinera dispersion, Phys. Rev. Lett., vol. 349 (1998), 4173-4177.

[19] D. D. Holm, J. E. Marsden And T. S. Ratiu, The Euler-Poincaé equations and semi-direct products with applications to continuum theories, Adv. Math., vol. 137 (1998), 1-81.

[20] P. E. KLOEDen, J. A. LANGA AND J. ReAL, Pullback $V$-attractors of the three-dimensional globally modified Navier-Stokes equations, Commun. Pure Appl. Anal., vol. 6 (2007), 937-955.

[21] P. E. Kloeden AND J. VAlero, The weak connectedness of the attainability set of weak solutions of the three-dimensional Navier-Stokes equations, Proc. R. Soc. Lond. Ser. A Math. Phys Engs. Sci., vol. 463 (2082) (2007), 1491-1508.

[22] P. E. Kloeden ANd J. A. LANGA, Flattening, squeezing and the existence of random attractors, Proc. R. Soc. Lond. Ser. A Math. Phys. Eng. Sci., vol. 463 (2007), 163-181.

[23] P. E. Kloeden, P. MARín-Rubio And J. Real, Equivalence of invariant measures and stationary statistical solutions for the autonomous globally modified Navier-Stokes equations, Commun. Pure Appl. Anal., vol. 8 (3) (2009), 785-802.

[24] O. A. Ladyzenskaya, The Mathematical Theory of Viscous Incompressible Flow, in: Mathematics and its Applucations, vol. 2, Gordon and Breach, Science Publishers, New York, London, Paris, 1969.

[25] J. L. Lions, Quelques Méthodes de Résolution des Problémes aux Limites Non Linéaires, Dunod, Paris, 1969.

[26] J. E. MARSDen AND S. ShKoller, Global well-posedness for the Lagrangian averaged NavierStokes (LANS- $\alpha$ ) equations on bounded domains, Phil. Trans. R. Soc. Lond. A., vol. 359 (2001), 1449-1468.

[27] P. Marín-Rubio, J. Real And A. M. Márquez-Durán, On the convergence of solutions of globally modified Navier-Stokes equations with delays to solutions of Navier-Stokes equations with delays, Adv. Nonlinear Stud., vol. 11 (4) (2011), 917-927.

[28] P. Marín-Rubio, A. M. Márquez And J. Real, Three dimensional system of globally modified Navier - Stokes equations with infinite delays, Discrete Contin. Dyn. Syst. Ser. B, vol. 14 (2010), 655-673.

[29] P. Marín-Rubio, J. Real and J. Valero, Pullback attractors for two-dimensional Navier-Stokes equations in an infinite delay case, Nonlinear Anal., vol. 74 (2011), 2012-2030.

[30] P. Marín-Rubio, A. M. Márquez And J. Real, Pullback attractors for globally modified NavierStokes equations with infinite delays, Discrete Contin. Dyn. Syst., vol. 31 (2011), 779-796.

[31] P. Marín-Rubio, A. M. Márquez And J. Real, Asymptotic behavior of solutions for a three dimensional system of globally modified Navier-Stokes equations with a locally Lipschitz delay term, Nonlinear Analysis, vol. 79 (2013),68-79.

[32] A. M. MÁRQUEZ, Existence and uniqueness of solutions, and pullback attractor for a system of globally modified 3D-Navier-Stokes equations with finite delay, SeMA J., vol. 51 (2010), 117-124.

[33] Shin.-I. PAI, Magnetogasdynamics and Plasma Dynamics, Springer-Verlag, Vienna, 1962, PrenticeHall, Inc., Englewood Cliffs, NJ.

[34] M. Romito, The uniqueness of weak solutions of the Globally modified Navier-Stokes equations, Adv. Nonlinear Stud., vol. 9 (2) (2009), 425-427.

[35] T. Silvertru Sever, Some Gronwall Type Inequalities and Applications, School of Communications and Informatics, November 7, 2002.

[36] M. Sermange, R. Temam, Some mathematical questions related to the MHD equations, Comm. Pure Appl. Math., vol. 36 (5) (1983), 635-664.

[37] T. TACHIM MEDjo, Unique strong and $\mathbb{V}$-attractor of a three dimensional globally modified CahnHilliard-Navier-Stokes model, Applicable Analysis, vol. 96 (16) (2017). 
[38] T. Tachim Medjo, A two-phase flow model with delays, Disc. and Cont. Dynam. Syst. Series B, vol. 22 (2017), 3273-3294.

[39] T. TACHIM MEDJo, Unique strong and $\mathbb{V}$-attractor of a three-dimensional globally modified twophase flow model, Annali di Mathematica vol. 197 (2018), 843-868.

[40] R. Temam, Navier-Stokes Equations. Theory and Numerical Analysis, in: Studies in Mathematics and its Applications, vol. 2, North-Holland Publishing Co., Amsterdam, New York, Oxford, 1977.

[41] R. Temam, Navier-Stokes Equations and Nonlinear Functional Analysis, Second Edition, SIAM, Philadelphia, 1995.

[42] R. TEMAM, Infinite dimensional dynamical systems in mechanics and physics, 2nd ed. vol. 68, Applied mathematics at science: Springer-Verlag, New York, 1997.

[43] R. Temam, Navier-Stokes equations, Theory and Numerical Analysis, AMS-Chelsea Series. AMS, Providence 2001.

[44] F. TONE, On the Long-Time $H^{2}$-Stability of the Implicit Euler Scheme for the 2D Magnetohydrodynamics Equations, J. Sci. Comput., vol. 38 (2009), 331-348.

[45] M. I. Vishik, A. I. Komech AND A. V. Fursikov, Some mathematical problems of statistical hydromechanics, Uspekhi Mat. Nauk. vol. 209 (5) (1979), 135-210.

[46] Z. ZHANG, Renormalized notes for Navier-Stokes equations by Roger Temam, Charl. Univ. Math. J., vol. 2 (2011). 